\title{
Serology-based criteria for adult coeliac disease have excellent accuracy across the range of pre-test probabilities
}

\section{Fuchs, Valma}

2019-02

Fuchs , V , Kurppa , K, Huhtala , H, Laurila , K, Maki , M , Collin , P , Salmi , T , Luostarinen , L , Saavalainen , P \& Kaukinen , K 2019 , ' Serology-based criteria for adult coeliac disease have excellent accuracy across the range of pre-test probabilities ', Alimentary Pharmacology \& Therapeutics , vol. 49 , no. 3 , pp. 277-284 . https://doi.org/10.1111/apt.15109

http://hdl.handle.net/10138/311292

https://doi.org/10.1111/apt.15109

unspecified

publishedVersion

Downloaded from Helda, University of Helsinki institutional repository.

This is an electronic reprint of the original article.

This reprint may differ from the original in pagination and typographic detail.

Please cite the original version. 


\title{
Serology-based criteria for adult coeliac disease have excellent accuracy across the range of pre-test probabilities
}

\author{
Valma Fuchs $^{1}$ | Kalle Kurppa ${ }^{2}$ (D) | Heini Huhtala ${ }^{3}$ | Kaija Laurila ${ }^{1}$ | Markku Mäki ${ }^{2}$ | \\ Pekka Collin $^{4}$ (D) | Teea Salmi ${ }^{1,5}$ | Liisa Luostarinen ${ }^{6}$ | Päivi Saavalainen ${ }^{7}$ | \\ Katri Kaukinen ${ }^{1,8}$
}

${ }^{1}$ Celiac Disease Research Center,Faculty of Medicine and Life Sciences, University of

Tampere,Tampere,Finland

${ }^{2}$ Tampere Center for Child Health Research, University of Tampere, and Department of Paediatrics, Tampere University Hospital, Tampere,Finland

${ }^{3}$ Tampere Faculty of Social Sciences, University of Tampere, Tampere, Finland

${ }^{4}$ Department of Gastroenterology and Alimentary Tract Surgery, Tampere

University Hospital, Tampere, Finland

${ }^{5}$ Department of Dermatology, Tampere University Hospital, Tampere, Finland

${ }^{6}$ Department of Neurology, Päijät-Häme Central Hospital, Lahti, Finland

${ }^{7}$ Research Programs Unit, Immunobiology, and Haartman Institute, Department of Medical Genetics, University of Helsinki, Helsinki, Finland

${ }^{8}$ Department of Internal Medicine, Tampere University Hospital, Tampere, Finland

\section{Correspondence}

Dr. Kalle Kurppa, Faculty of Medicine and Life Sciences, University of Tampere,

Tampere, Finland.

Email: kalle.kurppa@uta.fi

Funding information This study was supported by the Academy of Finland, the Sigrid Juselius Foundation, the Päivikki and Sakari Sohlberg Foundation, the Competitive State Research Financing of the Expert Area of Tampere University Hospital, the Finnish Medical Foundation, and the Foundation for Paediatric Research.

\section{Summary}

Background: The revised paediatric criteria for coeliac disease allow omission of duodenal biopsies in symptomatic children who have specific serology and coeliac disease-associated genetics. It remains unclear whether this approach is also applicable for adults with various clinical presentations.

Aim: To evaluate the accuracy of serology-based criteria in adults with variable pretest probabilities for coeliac disease.

Methods: Three study cohorts comprised adults with high-risk clinical coeliac disease suspicion ( $n=421)$, moderate-risk family members of coeliac disease patients ( $n=2357)$, and low-risk subjects from the general population $(n=2722)$. Serological and clinical data were collected, and "triple criteria" for coeliac disease comprised transglutaminase 2 antibodies $>10 x$ the upper limit of normal, positive endomysium antibodies, and appropriate genetics without requirement of symptoms. The diagnosis was based on intestinal biopsy.

Results: The diagnosis of coeliac disease was established in 274 subjects. Of these, 59 high-risk subjects, 17 moderate-risk subjects, and 14 low-risk subjects fulfilled the "triple criteria". All had histologically proven coeliac disease, giving the criteria a positive predictive value of $100 \%$. Altogether, 90 (33\%) of all 274 newly diagnosed patients could have avoided biopsy, including 37\% among high-risk, $20 \%$ among moderate-risk, and $48 \%$ among low-risk patients. No histological findings other than coeliac disease were found in the biopsies of "triple positive" subjects.

Conclusions: Coeliac disease can reliably and safely be diagnosed without biopsy in adults fulfilling the "triple criteria" regardless of the pre-test probability. Revised criteria would enable the number of endoscopies to be reduced by one-third. 


\section{1 | INTRODUCTION}

The true prevalence of coeliac disease is known to be as high as 1\%$2 \%$, emphasising the importance of practical and cost-effective diagnostic policy. On the other hand, since the treatment consists of a lifelong and restrictive gluten-free diet, the diagnosis should be highly accurate. Demonstration of small-bowel mucosal damage has been the gold standard for the diagnosis for a long time. This invasive histologybased approach contains, however, some limitations. The required duodenal lesion is a characteristic but not specific finding, as it can be caused also by other conditions and medicines. ${ }^{1}$ In addition, gradual development or patchy mucosal damage and inadequate or poorly orientated biopsy specimen may result in misdiagnosis. ${ }^{2,3}$

Tests for serum autoantibodies against tissue transglutaminase 2 (tTG-ab) and endomysium (EMA) have become widely available for first-line screening of coeliac disease. These tests, especially EMA and high positive values of tTG-ab, have been found to possess excellent diagnostic accuracy. ${ }^{4,5}$ Due to this and the aforesaid problems with the histology-based diagnosis, the European Society for Paediatric Gastroenterology Hepatology and Nutrition (ESPGHAN) established in 2012 new criteria stating that the biopsy could be avoided in symptomatic children with tTG-ab value more than 10 times the upper limit of normal (ULN), positive EMA, and coeliactype genotype. ${ }^{6}$ There is increasing evidence to support the accuracy of these guidelines for paediatric coeliac disease if applied meticulously. ${ }^{7,8}$

Whether the nonbiopsy approach could be applicable also in adult coeliac disease remains controversial. ${ }^{9}$ An unsolved issue even with the paediatric criteria is their feasibility in populations with variable pre-test probabilities, including screen-detected and asymptomatic subjects, as this might affect the accuracy of serological testing. ${ }^{10,11}$ We investigated the applicability of the nonbiopsy approach and its impact on reducing the number of endoscopies in three large adult cohorts, including high-risk subjects with clinical suspicion of coeliac disease, moderate-risk subjects with family history of the disease, and low-risk individuals participating in population-based screening.

\section{2 | MATERIALS AND METHODS}

\section{1 | Participants and study design}

The study comprised altogether 5500 adults who had no previous coeliac disease or dermatitis herpetiformis diagnosis and were on a gluten-containing diet. The whole cohort was formed by evaluating retrospectively the data of three, originally prospectively collected subgroups with different pre-test probabilities for coeliac disease:

1. The high-risk cohort comprised 421 adults referred to the Department of Gastroenterology and Alimentary Tract Surgery, Tampere University Hospital, for further serological and endoscopic investigations due to variable clinical symptoms and signs compatible with coeliac disease such as diarrhoea, loose stools, abdominal pain, dyspepsia, flatulence, or malabsorption. Based on previous literature, the prevalence of coeliac disease in such pre-selected patients varies approximately between $5 \%$ and $50 \%$ depending on the setting and population in question. ${ }^{12,13}$ Even though about one half of high-risk subjects had been pretested for coeliac disease serology, clinical presentation was the defining characteristic as also subjects with negative antibody results were referred for endoscopies. All subjects underwent routine clinical evaluation, determination of coeliac disease serology, and disease-associated genetics. Furthermore, upper gastrointestinal endoscopy with duodenal biopsies were offered regardless of serology results.

2. The moderate-risk cohort (at-risk family members) was collected by nationwide recruitment of 2357 family members of 730 previously diagnosed coeliac disease patients via newspaper advertisements and from the Finnish coeliac society as described elsewhere. ${ }^{14}$ According to a recent meta-analysis, the pooled prevalence of coeliac disease is $7.5 \%$ in this at-risk group. ${ }^{15}$ The family study was coordinated by the Tampere Celiac Disease Research Center. Coeliac disease-associated serology and genetics were measured from all voluntary family members and endoscopy was offered to seropositive subjects.

3. The low pre-test probability cohort comprised 4272 randomly selected 51 to 76-year-old individuals living in the Päijät-Häme Hospital district. The cohort representing the ageing Finnish general population was originally collected for a research project aiming to improve health and well-being, not especially for coeliac disease research. ${ }^{16}$ Of them, coeliac disease autoantibodies were screened from altogether 2722 nonselected subjects who had no previous contact to health care due to coeliac disease related symptoms. The prevalence of coeliac disease in this cohort (2\%) has been shown to be comparable with the general Finnish population. ${ }^{17}$ Seropositive subjects were offered determination of genotype and endoscopy.

\subsection{Clinical data}

All subjects with a clinical suspicion of coeliac disease and at-risk family members were interviewed for their clinical presentation and family history of coeliac disease. In the low-risk population cohort, the interview was carried out only with volunteered seropositive subjects. In addition, all newly diagnosed coeliac disease patients underwent assessment of adherence to the gluten-free diet and of clinical, serological, and histological response 1 year after the diagnosis. Adequate response was defined as normalisation or marked decrease in antibody levels, recovery from the intestinal mucosal damage, and symptom alleviation.

\section{3 | Serological tests and genotyping}

In the high-risk and low-risk study groups, serum tTG-ab was detected by Celikey ${ }^{\circledR}$ ELISA (Phadia, Freiburg, Germany) having a 
ULN of $5 \mathrm{U} / \mathrm{mL}$ to indicate tTG-ab positivity. ${ }^{18}$ In the moderate-risk group, tTG-ab was first measured with a sensitive Quanta Lite ${ }^{\circledR}$ ELISA test (INOVA diagnostics, San Diego, CA, USA). To unify the results, all 403 samples positive $(>20 \mathrm{U} / \mathrm{mL})$ for Quanta Lite ${ }^{\circledR}$ and 450 additional randomly chosen negative samples were re-tested with Celikey ${ }^{\circledR}$. EMAs were determined by an indirect immunofluorescence method using human umbilical cord as antigen as previously described. ${ }^{19}$ Dilution of $1: \geq 5$ was considered positive.

Coeliac disease-associated HLA genotyping was performed by the DELFIA Celiac Disease Hybridization Assay (PerkinElmer Life and Analytical Sciences, Wallac Oy, Turku, Finland) or with the Olerup SSP DQ low-resolution kit (Olerup SSP AB, Stockholm, Sweden).

"Triple criteria" were defined as tTG-ab value $>50 \mathrm{U} / \mathrm{mL}$ which is equal to Celikey ${ }^{\circledR}>10 \times$ ULN, positive EMA and presence of HLA DQ2/DQ8, regardless of the clinical presentation. For the moderaterisk cohort, the accuracy of the triple criteria was tested also with QuantaLite $^{\circledR}$, where tTG-ab $>10 \times$ ULN was attained at $>200 \mathrm{U} / \mathrm{mL}$.

\section{4 | Histology}

According to our clinical routine, a minimum of four representative small-bowel mucosal biopsies are taken upon oesophagogastroduodenoscopy from the distal duodenum. Well-orientated samples ${ }^{3}$ are paraffin-embedded, stained by haematoxylin-eosin and studied under a light microscope. In the present study, the reference standard for coeliac disease diagnosis was considered Marsh grade $\geq 2 .^{6}$ In cases having only coeliac-type mucosal inflammation (Marsh 1 ), the diagnosis was established if the disease was clinically and histologically aggravated on a gluten-containing diet. ${ }^{20,21}$

\subsection{Occurrence of coeliac disease}

The proportion of new coeliac disease patients that could be diagnosed with the "triple criteria" was evaluated for each cohort. All in the high-risk group underwent endoscopy and the total prevalence of coeliac disease was calculated. In the family-risk and populationbased cohorts, only seropositive patients were biopsied and the number of possible seronegative coeliac disease patients could not be evaluated.

\subsection{Statistics}

Statistical analysis was carried out using SPSS version 20.0 (IBM, Armonk, NY, USA). The distribution of general characteristics of the subjects was presented as percentages, medians, and ranges as appropriate. For all cohorts, the positive predictive value (PPV) of the "triple criteria" for biopsy-proven coeliac disease was calculated as follows: PPV $=a /(a+b)$, where " $a$ " is the "true positives", referring to biopsy-proven coeliac disease and " $b$ " is the "false positives", referring to histology without evident coeliac disease. A $95 \% \mathrm{Cl}$ (confidence interval) for PPV was assessed in all three cohorts according to the number of "triple positive" patients. Additionally, the lowest tTG-ab level giving a 100\% PPV was determined. All data were coded and analysed blinded.

\subsection{Ethical aspects}

The study design and patient recruitment were approved by the Regional Ethics Committees of Pirkanmaa Hospital District and Päijät-Häme Central Hospital. All participants gave written informed consent.

\section{RESULTS}

Clinical characteristics of the 5500 enrolled participants are shown in Table 1. There were more women in the clinically investigated high-risk cohort and, by definition, higher median age in the low-risk population cohort compared to the other groups (Table 1).

\subsection{PPV of the "triple criteria" for coeliac disease}

\subsection{1 | High-risk cohort: clinical suspicion}

Altogether 133 of 421 clinically suspected participants had positive tTG-ab, with a value of $>10 \times$ ULN in 60 (45\%) of the 133 (Figure 1). All 60 had coeliac-type HLA and all but one positive EMA. At endoscopy, coeliac disease was initially found in 56 (95\%) of 59, but also the remaining three "triple positive" subjects with only Marsh I lesion were subsequently diagnosed with coeliac disease since they developed Marsh III lesion during one further year on a gluten-containing diet. Thus, eventually all 59 patients received coeliac disease diagnosis, giving a PPV of 100\% (Cl 94\%-100\%) for "triple positivity" (Figure 1).

\subsection{2 | Moderate-risk cohort: at-risk family members}

TTG-ab positivity with Celikey ${ }^{\circledR}$ was seen in 93 of the 2357 family members; 24 (26\%) of these fulfilled the "triple criteria" (Figure 1). However, seven of 24 were not biopsied and were excluded from further analysis: five refused, one deceased, and one had already initiated a gluten-free diet by himself before endoscopy. All remaining

TABLE 1 Clinical characteristics of the three study cohorts with different pre-test probabilities for coeliac disease

\begin{tabular}{|c|c|c|c|}
\hline Pre-test probability & $\begin{array}{l}\text { High: } \\
\text { clinical } \\
\text { suspicion } \\
\text { n = } 421\end{array}$ & $\begin{array}{l}\text { Moderate: } \\
\text { at-risk } \\
\text { group }^{a} \\
\mathrm{n}=2357\end{array}$ & $\begin{array}{l}\text { Low: } \\
\text { population } \\
\text { cohort } \\
n=2722\end{array}$ \\
\hline Age, median (range), years & $46(18-83)$ & $45(18-96)$ & $63(51-76)$ \\
\hline Female, \% & 71 & 57 & 53 \\
\hline $\begin{array}{l}\text { Family history for coeliac } \\
\text { disease, } \%\end{array}$ & 14 & 100 & No data \\
\hline
\end{tabular}

${ }^{a}$ First and second degree relatives of coeliac disease patients. 


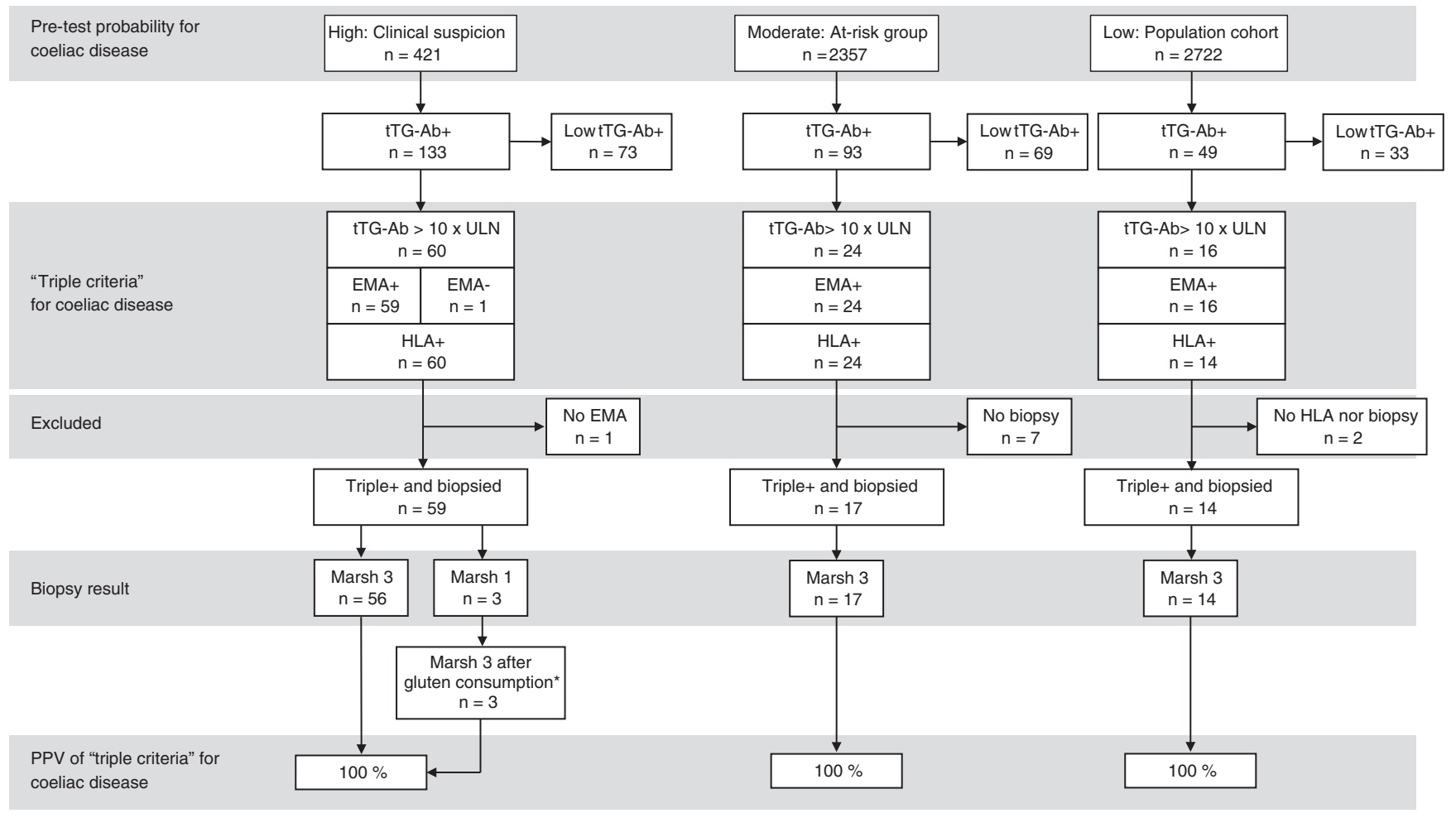

FIGURE 1 Study design and main results of the positive predictive value for "triple positive" nonbiopsy diagnostic criteria of coeliac disease in three adult cohorts. "Triple positivity" comprises tTG-ab >10× ULN, positive EMA, and HLA genotype DQ2/DQ8. Abbreviations: tTG-ab+, positive tissue transglutaminase antibodies; ULN, upper limit of normal; EMA+, positive endomysium antibodies; HLA, human leucocyte antigen; GFD, gluten-free diet. *Patients continued normal gluten intake until follow-up biopsies after 1 year were performed

17 subjects were found to have biopsy-proven coeliac disease (PPV 100\%, Cl 82\%-100\%). TTG-ab values did not differ between biopsied and nonbiopsied subjects (median 83 vs $90 \mathrm{U} / \mathrm{mL}, P=0.658$ ).

With QuantaLite ${ }^{\circledR},>10 \times$ ULN (>200 U/mL) was achieved in 29 of the 93 subjects, all of whom were triple positive. Biopsy was available from 20 patients who all had Marsh III lesions, resulting in a PPV of $100 \%$ (Cl 84\%-100\%) for the triple criteria.

\subsection{3 | Low-risk cohort: screened general population}

Forty-nine (2\%) of the 2722 screened subjects had elevated tTG-ab. Sixteen $(33 \%)$ of these had tTG-ab $>10 \times$ ULN and positive EMA, but two subjects withdrew from the study before HLA testing and endoscopy. The remaining 14 were "triple positive" and had histologically confirmed coeliac disease, resulting in PPV of $100 \%(\mathrm{Cl} 78 \%$ $100 \%$ ) (Figure 1). The two nonbiopsied subjects had comparable tTG-ab values with those undergoing endoscopy (100 and $82 \mathrm{U} / \mathrm{mL}$ vs median $91 \mathrm{U} / \mathrm{mL}, P=0.883$ ).

\subsection{Clinical characteristics of the triple positive subjects}

In detailed analysis of the 90 "triple positive" subjects, as in the whole study cohort, there were more women among the high-risk subjects and higher median age among the low-risk subjects
(Table 2). Despite of being screen-detected, most family members and population-based subjects reported some clinical symptoms when requested and only $43 \%$ and $29 \%$, were eventually asymptomatic respectively. Family history for coeliac disease was common also in clinically detected and population-screened patients (Table 2). No clinically significant endoscopic or histological findings other than those related to coeliac disease were exposed in either diagnostic or follow-up biopsies.

\subsection{Prevalence of coeliac disease and proportion of triple positive patients}

The total number of new biopsy-proven coeliac disease patients detected in our three cohorts was 274 , of whom the "triple criteria" were fulfilled in 90 (33\%) (Table 3). All subjects in the high-risk cohort were biopsied and 160 (38\%) of them were found to have coeliac disease. In the family risk and population cohorts, only seropositive subjects were biopsied and 85 (3.6\%) and 29 (1.1\%) were found to have coeliac disease respectively.

\section{4 | Lowest tTG-ab value resulting in 100\% PPV for triple criteria}

All biopsied subjects with $\mathrm{tTG}-\mathrm{ab} \geq 7 \mathrm{U} / \mathrm{mL}$ in the high- and moderate-risk cohorts had histologically proven coeliac disease. The corresponding value in the low-risk cohort was $17 \mathrm{U} / \mathrm{mL}$ (3.3× ULN with 
TAB LE 2 Clinical characteristics of 90 biopsied study subjects fulfilling triple criteria ${ }^{a}$ for coeliac disease diagnosis in different pretest probability cohorts

\begin{tabular}{|c|c|c|c|}
\hline Pre-test probability & $\begin{array}{l}\text { High: } \\
\text { clinical } \\
\text { suspicion } \\
\mathrm{n}=59\end{array}$ & $\begin{array}{l}\text { Moderate: } \\
\text { at-risk } \\
\text { group }^{b} \\
\mathrm{n}=17\end{array}$ & $\begin{array}{l}\text { Low: } \\
\text { population } \\
\text { cohort } \\
n=14\end{array}$ \\
\hline Age, median (range), years & $47(18-74)$ & $46(21-59)$ & $62(54-75)$ \\
\hline Female, \% & 80 & 65 & 64 \\
\hline \multicolumn{4}{|l|}{ Main clinical presentation, \% } \\
\hline Gastrointestinal & 73 & 71 & 57 \\
\hline Malabsorption & 34 & 24 & 0 \\
\hline Extraintestinal & 19 & 12 & 0 \\
\hline Asymptomatic & 0 & 29 & 43 \\
\hline $\begin{array}{l}\text { Family history of coeliac } \\
\text { disease, } \%\end{array}$ & 22 & 100 & 29 \\
\hline
\end{tabular}

${ }^{\text {a }}$ Transglutaminase 2 antibodies $>10 \times$ upper limit of normal, positive endomysium antibodies, and coeliac disease-associated genotype.

${ }^{b}$ First and second degree relatives of coeliac disease patients

Celikey ${ }^{\circledR}$ ), which was thus the lowest value for $100 \%$ PPV in the whole study cohort. Subjects in the moderate-risk cohort were initially tested with QuantaLite ${ }^{\circledR}$, which gave the lowest tTG-ab level for $100 \%$ PPV at $106 \mathrm{U} / \mathrm{mL}$, equalling $5.3 \times$ ULN.

\section{DISCUSSION}

We found that accurate non-invasive coeliac disease diagnosis can be established in "triple positive" adults regardless of the pre-test probability. The paediatric criteria are currently restricted to clinically suspected subjects. ${ }^{6}$ Recent evidence suggests they could be extended to asymptomatic children, ${ }^{7,22,23}$ although this has also been questioned. ${ }^{10}$ Here, the criteria worked equally well in adults with and without apparent symptoms, and while our study was not designed for asymptomatic patients, we consider such a dichotomous categorisation problematic. As was seen here and also previously, ${ }^{24}$ screen-detected patients often have unrecognised symptoms and, vice versa, some patients are clinically detected due to asymptomatic signs such as anaemia or osteoporosis. ${ }^{25,26}$ Definition of symptoms and their association with coeliac disease are challenging, as the clinical and histological presentation may not correlate and symptoms can fluctuate or not be recognised until their alleviation on a gluten-free diet. ${ }^{26}$ Abdominal complaints are also frequent in the general population, have low PPV for coeliac disease, and case finding based on them is ineffective. ${ }^{27,28}$ Thus, inflexible grouping of patients to "asymptomatic" and symptomatic corresponds poorly to the clinical reality and does not improve diagnostic accuracy, particularly in EMA-positive subjects. ${ }^{21}$ Based on this, categorising the clinically suspected cohort as "high risk" due to symptoms is somewhat debatable, especially as many subjects had been serologically pretested. Nevertheless, $38 \%$ of the cohort eventually had coeliac disease, demonstrating successful labelling as "high risk".
TABLE 3 New biopsy-proven coeliac disease patients in three study cohorts with different pre-test probabilities and the proportion of "triple positive" cases ${ }^{2}$

\begin{tabular}{|c|c|c|c|c|}
\hline $\begin{array}{l}\text { Pre-test } \\
\text { probability }\end{array}$ & $\begin{array}{l}\text { High: } \\
\text { clinical } \\
\text { suspicion } \\
n=160\end{array}$ & $\begin{array}{l}\text { Moderate: } \\
\text { at-risk } \\
\text { group }^{b} \\
n=85\end{array}$ & $\begin{array}{l}\text { Low: } \\
\text { population } \\
\text { cohort } \\
n=29\end{array}$ & $\begin{array}{l}\text { Total } \\
\text { coeliac } \\
\text { disease } \\
\text { patients } \\
\mathrm{n}=274\end{array}$ \\
\hline $\begin{array}{l}\text { "Triple } \\
\text { positive", n }\end{array}$ & 59 & 17 & 14 & 90 \\
\hline $\begin{array}{l}\text { Positive tTG-ab } \\
\text { not fulfilling } \\
\text { "triple } \\
\text { positivity", n }\end{array}$ & 68 & 48 & 15 & 166 \\
\hline $\begin{array}{l}\text { Negative tTG- } \\
\text { ab, positive } \\
\text { EMA, n }\end{array}$ & 16 & 18 & 0 & 34 \\
\hline $\begin{array}{l}\text { Negative tTG- } \\
\text { ab, negative } \\
\text { EMA, n }\end{array}$ & 17 & 1 & 0 & 18 \\
\hline $\begin{array}{l}\text { "Triple } \\
\text { positive" out } \\
\text { of total } \\
\text { patients }\end{array}$ & $37 \%$ & $20 \%$ & $48 \%$ & $33 \%$ \\
\hline
\end{tabular}

${ }^{\text {aT }}$ Transglutaminase 2 antibodies (tTG-ab, Celikey ${ }^{\circledR}$ ) $>10 x$ upper limit of normal, positive endomysium antibodies (EMA), and coeliac disease-associated genotype.

${ }^{\mathrm{b}}$ First and second degree relatives of coeliac disease patients.

We believe that a major contributor for the 100\% PPV for the "triple criteria" was the use of validated serological and histopathologic methods as recommended. ${ }^{6}$ For example, some studies reporting lower PPV have used arbitrary cut-offs such as $100 \mathrm{U} / \mathrm{mL}$ for tTG-ab instead of $>10 \times$ ULN. $^{29}$ Currently there is no standardisation for tTG-ab tests and their optimal ULN varies, ${ }^{6}$ as demonstrated by the differences between the two kits in the present study. In fact, even the $10 \times$ is rigid and was chosen more to be on a "safe side", 6,7 as setting test-specific thresholds would be challenging. In Finland, public laboratories use certificated quality control by outside accreditors to evaluate the performance of test kits and their application. ${ }^{30}$ The ESPGHAN criteria require disease-specific EMA partly due to the nonstandardisation and variable performances of the tTG-ab assays. ${ }^{6}$ Unfortunately, not all studies evaluating the criteria have included EMA. ${ }^{10}$ In line with paediatric studies, ${ }^{7,8}$ we observed excellent agreement between EMA positivity and tTG-ab $>10 \times$ ULN, giving further credibility for the results. One might ask whether laborious EMA was required in all cases, but currently it could be considered as inexpensive quality control. In contrast, HLA testing seems to add minimal value in adults with high tTG-ab values and positive EMA, similarly as recently shown in children. ${ }^{7}$ Therefore, genotyping could be restricted to exclude coeliac disease in unclear cases. ${ }^{7,31}$

Another explanation for suboptimal PPV for serology in some studies could lie in the use of error-prone biopsy results as the gold standard. ${ }^{3,32}$ Accordingly, Werkstetter et $\mathrm{al}^{7}$ observed remarkable variability in histopathological analyses between local and centralised 
providers even in a pre-planned research setting. Only a few studies evaluating the nonbiopsy criteria have given satisfactory data on this issue, including the number and location of biopsies, handling and orientation of the samples, and histological interpretation. Hence, some cases considered to have "false-positive serology" might actually have false-negative histology, ${ }^{3,33}$ giving thus misleading PPVs. In fact, objective serology could offer more accurate diagnostics in clinical routine where it is challenging to apply laborious and expertiserequiring histopathology with the increasing number of patients.

Altogether $33 \%$ of new coeliac disease patients could have been diagnosed applying the "triple criteria", which might be even a conservative estimation as some subjects with a high likelihood for coeliac disease withdrew before the endoscopy. In the population-based low-risk cohort, the figure (48\%) was close to that seen in paediatric studies. ${ }^{7,34}$ Besides being easier for patients, reduced endoscopies could provide substantial healthcare savings, as it is estimated that up to $95 \%$ of diagnostic expenses could be spared by omitting the biopsy. ${ }^{22}$ The released healthcare resources could be redirected for example to the follow-up of the increasing number of inflammatory bowel disease patients. ${ }^{35}$ It is feared that ceasing referrals for biopsy would lead to missing coeliac disease, or that patients might not approve a serology-based diagnosis. ${ }^{9,36}$ On the contrary, there is evidence that an active role of primary care actually improves case finding, and effective and acceptable diagnostics is more a matter of education and close collaboration with primary health care. ${ }^{37,38}$

There are also other nondiagnostic reasons why retaining the biopsy has been advocated, ${ }^{39}$ including fear of missing a concomitant disorder ${ }^{9}$ or complication such as refractory coeliac disease and malignancy. ${ }^{40}$ Evidently, coexistence of two conditions is possible, but performing endoscopy to all "triple criteria" positive individuals does not seem justified. None of the patients who could have avoided the biopsy were found to have any comorbidities in the diagnostic endoscopy, and these have been extremely rare also in previous studies. ${ }^{11,40,41}$ Further investigations are obviously indicated in case of red flag symptoms such as bloody stools, dysphagia, or severe weight loss, with extra caution in elderly who are at greater risk for malignancies. ${ }^{11,42}$ As a comparison, patients with gastrointestinal reflux are rarely referred directly to endoscopy without red flag symptoms. ${ }^{43}$ The diagnosis of refractory coeliac disease is based on poor clinical response and severe histopathologic findings despite the gluten-free diet, and baseline biopsy results would not be helpful. ${ }^{44}$ Elfström et al suggested that the biopsy could have prognostic value for lymphoproliferative malignancies, but they compared patients having potential coeliac disease with normal mucosal architecture to those with flat mucosa. ${ }^{45}$ Elsewhere, the severity of established villous atrophy at diagnosis did not affect the complication risk. ${ }^{46}$ Further, to emphasise, the aim was not to entirely abandon the biopsy but to provide easier and more cost-effective diagnostics, and if any concerns arise, endoscopy should be performed with a low threshold.

Our main strength was the utilisation of three large cohorts comprising patients with varying diagnostic approaches and pre-test probabilities. Moreover, serology was used as recommended, validated histopathological methods were used, and subjects not fulfilling the "triple criteria" were carefully excluded. However, there were also limitations. Serology was not measured from two separate samples as ESPGHAN instructs, although currently there are no instructions how to operate with possible conflicting results and it remains unclear if this would be necessary. ${ }^{6}$ The prevalence of coeliac disease in moderate and low-risk cohorts was lower than expected as subjects with a previous diagnosis were excluded. In theory, such exclusion might cause some selection bias, as also could $30 \%$ of moderate risk and $13 \%$ of low risk "triple positive" patients who were not biopsied. Even though there are no indicators to suspect selection in these screenbased cohorts, applicability of the criteria to nonbiopsied subjects is not $100 \%$ sure. Due to the withdrawals among subjects who did and also those who did not fulfil the "triple criteria", estimating percentages for avoidable biopsies was not possible. Altogether, the number of triple positive subjects in the moderate and low-risk cohorts was quite small, giving wide theoretical confidence intervals. Moreover, exact clinical information was available only for biopsied subjects in these cohorts. Finally, it must be stressed that our results can be generalised only to centres using accredited labs and test kits with linear calibration curves allowing to use multiples of ULN.

To conclude, we demonstrated that reliable nonbiopsy diagnosis of coeliac disease is possible in adults regardless of their clinical presentation or assumed pre-test probability for the disease. Applying such serology-based approach would lead to substantially reduced number of endoscopies and subsequent healthcare savings without affecting the diagnostic accuracy. Our findings of the applicability of tTG-ab $>10 \times$ ULN with positive EMA are a promising start, but we believe that extending biopsy-omitting diagnostics to even more patients could be expected in the future.

\section{ACKNOWLEDGEMENTS}

Declaration of personal interests: None.

\section{AUTHORSHIP}

Guarantor of the article: Kalle Kurppa.

Authors' contributions: Katri Kaukinen and Kalle Kurppa designed and supervised the study. Kaija Laurila, Teea Salmi, Markku Mäki, Pekka Collin and Liisa Luostarinen organised the data collection. Päivi Saavalainen performed genetic testing. Heini Huhtala provided expertise in statistical analysis and interpretation. Valma Fuchs drafted this paper, which was revised for important intellectual content by all the other authors.

All authors approved the final version of the manuscript..

\section{ORCID}

Kalle Kurppa (iD https://orcid.org/0000-0003-4757-2164

Pekka Collin (iD https://orcid.org/0000-0002-4872-0416 


\section{REFERENCES}

1. Biagi $\mathrm{F}$, Bianchi $\mathrm{PI}$, Campanella J, et al. The prevalence and the causes of minimal intestinal lesions in patients complaining of symptoms suggestive of enteropathy: a follow-up study. J Clin Pathol. 2008;61:1116-1118.

2. Ravelli A, Villanacci V, Monfredini C, et al. How patchy is patchy villous atrophy?: distribution pattern of histological lesions in the duodenum of children with celiac disease. Am J Gastroenterol. 2010;105:2103-2110.

3. Taavela J, Koskinen $\mathrm{O}$, Huhtala $\mathrm{H}$, et al. Validation of morphometric analyses of small-intestinal biopsy readouts in celiac disease. PLoS ONE. 2013;8:e76163.

4. Salmi TT, Collin P, Reunala T, et al. Diagnostic methods beyond conventional histology in coeliac disease diagnosis. Dig Liver Dis. 2010;42:28-32.

5. Alessio MG, Tonutti E, Brusca I, et al. Correlation between IgA tissue transglutaminase antibody ratio and histological finding in celiac disease. J Pediatr Gastroenterol Nutr. 2012;55:44-49.

6. Husby S, Koletzko S, Korponay-Szabo IR, et al. European society for pediatric gastroenterology, hepatology, and nutrition guidelines for the diagnosis of coeliac disease. J Pediatr Gastroenterol Nutr. 2012;54:136-160.

7. Werkstetter KJ, Korponay-Szabo IR, Popp A, et al. Accuracy in diagnosis of celiac disease without biopsies in clinical practice. Gastroenterology. 2017;153:924-935.

8. Wolf J, Petroff D, Richter T, et al. Validation of antibody-based strategies for diagnosis of pediatric celiac disease without biopsy. Gastroenterology. 2017;153:419.e17.

9. Marks LJ, Kurien M, Sanders DS. The serological diagnosis of adult coeliac disease - a cautious step forward? Gastroenterol Hepatol Bed Bench. 2018;11:175-177.

10. Fernandez-Banares F, Alsina M, Modolell I, et al. Are positive serumIgA-tissue-transglutaminase antibodies enough to diagnose coeliac disease without a small bowel biopsy? Post-test probability of coeliac disease. J Crohns Colitis. 2012;6:861-866.

11. Tortora R, Imperatore N, Capone $\mathrm{P}$, et al. The presence of anti-endomysial antibodies and the level of anti-tissue transglutaminases can be used to diagnose adult coeliac disease without duodenal biopsy. Aliment Pharmacol Ther. 2014;40:1223-1229.

12. Collin $\mathrm{P}$, Rasmussen $\mathrm{M}$, Kyrönpalo $\mathrm{S}$, et al. The hunt for coeliac disease in primary care. QJM. 2002;95:75-77.

13. Hopper AD, Cross SS, Hurlstone DP, et al. Pre-endoscopy serological testing for coeliac disease: evaluation of a clinical decision tool. BMJ. 2007;334:729.

14. Paarlahti P, Kurppa K, Ukkola A, et al. Predictors of persistent symptoms and reduced quality of life in treated coeliac disease patients: a large cross-sectional study. BMC Gastroenterol. 2013;13:75.

15. Singh P, Arora S, Lal S, et al. Risk of celiac disease in the firstand second-degree relatives of patients with celiac disease: a systematic review and meta-analysis. $A m$ J Gastroenterol. 2015;110:1539-1548.

16. Vilppula A, Collin P, Mäki M, et al. Undetected coeliac disease in the elderly: a biopsy-proven population-based study. Dig Liver Dis. 2008;40:809-813.

17. Lohi S, Mustalahti K, Kaukinen K, et al. Increasing prevalence of coeliac disease over time. Aliment Pharmacol Ther. 2007;26:1217-1225.

18. Mäki M, Mustalahti K, Kokkonen J, et al. Prevalence of coeliac disease among children in Finland. N Engl J Med. 2003;348:2517-2524.

19. Ladinser B, Rossipal E, Pittschieler K. Endomysium antibodies in coeliac disease: an improved method. Gut. 1994;35:776-778.

20. Ludvigsson JF, Bai JC, Biagi F, et al. Diagnosis and management of adult coeliac disease: guidelines from the British society of gastroenterology. Gut. 2014;63:1210-1228.
21. Kurppa K, Collin P, Viljamaa M, et al. Diagnosing mild enteropathy celiac disease: a randomized, controlled clinical study. Gastroenterology. 2009;136:816-823.

22. Paul SP, Sandhu BK, Spray CH, et al. Evidence supporting serology based pathway for diagnosing coeliac disease in asymptomatic children from high-risk groups. J Pediatr Gastroenterol Nutr. 2018;66:641-644.

23. Trovato CM, Montuori M, Anania C, et al. Are ESPGHAN "biopsysparing" guidelines for celiac disease also suitable for asymptomatic patients? Am J Gastroenterol. 2015;110:1485-1489.

24. Agardh D, Lee HS, Kurppa K, et al. Clinical features of celiac disease: a prospective birth cohort. Pediatrics. 2015;135:627-634.

25. Mustalahti K, Collin P, Sievänen $\mathrm{H}$, et al. Osteopenia in patients with clinically silent coeliac disease warrants screening. Lancet. 1999;354:744-745.

26. Kurppa K, Paavola A, Collin P, et al. Benefits of a gluten-free diet for asymptomatic patients with serologic markers of celiac disease. Gastroenterology. 2014;147:617.e1.

27. Rosen A, Sandström O, Carlsson A, et al. Usefulness of symptoms to screen for celiac disease. Pediatrics. 2014;133:211-218.

28. Hujoel IA, Van Dyke CT, Brantner T, et al. Natural history and clinical detection of undiagnosed coeliac disease in a North American community. Aliment Pharmacol Ther. 2018;47:1358-1366.

29. Donaldson MR, Book LS, Leiferman KM, et al. Strongly positive tissue transglutaminase antibodies are associated with marsh 3 histopathology in adult and pediatric celiac disease. J Clin Gastroenterol. 2008:42:256-260.

30. Bizzaro N, Bossuyt X, Haapala AM, et al. Accreditation in autoimmune diagnostic laboratories. A position paper of the European Autoimmunity Standardisation Initiative (EASI). Autoimmun Rev 2017;16:81-86.

31. Egner W, Shrimpton A, Sargur R, et al. ESPGHAN guidance on coeliac disease 2012: multiples of ULN for decision making do not harmonise assay performance across centres. J Pediatr Gastroenterol Nutr. 2012;55:733-735.

32. Dong $\mathrm{YH}$, Jin $\mathrm{Y}$, Tsacogianis $\mathrm{TN}$, et al. Use of olmesartan and enteropathy outcomes: A multi-database study. Aliment Pharmacol Ther. 2018;47:792-800

33. Koletzko S, Auricchio R, Dolinsek J, et al. No need for routine endoscopy in children with celiac disease on a gluten-free diet. J Pediatr Gastroenterol Nutr. 2017;65:267-269.

34. Gidrewicz D, Potter K, Trevenen CL, et al. Evaluation of the ESPGHAN celiac guidelines in a North American pediatric population. Am J Gastroenterol. 2015;110:760-767.

35. Molodecky NA, Soon IS, Rabi DM, et al. Increasing incidence and prevalence of the inflammatory bowel diseases with time, based on systematic review. Gastroenterology. 2012;142:46-54.

36. Biagi $\mathrm{F}$, Bianchi PI, Campanella J, et al. The impact of misdiagnosing celiac disease at a referral centre. Can J Gastroenterol. 2009;23:543545.

37. Holmes GKT, Forsyth JM, Knowles S, et al. Coeliac disease: further evidence that biopsy is not always necessary for diagnosis. Eur J Gastroenterol Hepatol. 2017;29:640-645.

38. Hin H, Bird G, Fisher P, et al. Coeliac disease in primary care: case finding study. BMJ. 1999;318:164-167.

39. Kurien M, Ludvigsson JF, Sanders DS, et al. A no biopsy strategy for adult patients with suspected coeliac disease: making the world gluten-free. Gut. 2015;64:1003-1004

40. Efthymakis K, Serio M, Milano A, et al. Application of the biopsysparing ESPGHAN guidelines for celiac disease diagnosis in adults: a real-life study. Dig Dis Sci. 2017;62:2433-2439.

41. Salo M, Collin P, Kyrönpalo $S$, et al. Age, symptoms and upper gastrointestinal malignancy in primary care endoscopy. Scand J Gastroenterol. 2008;43:122-127. 
42. Collin P, Vilppula A, Luostarinen L, et al. Review article: coeliac disease in later life must not be missed. Aliment Pharmacol Ther. 2018;47:563-572.

43. Gyawali CP, Fass R. Management of gastroesophageal reflux disease. Gastroenterology. 2018;154:302-318.

44. Rubio-Tapia A, Murray JA. Classification and management of refractory coeliac disease. Gut. 2010;59:547-557.

45. Elfström P, Granath F, Ekström Smedby K, et al. Risk of lymphoproliferative malignancy in relation to small intestinal histopathology among patients with celiac disease. I Natl Cancer Inst. 2011;103:436-444.

46. Ilus $\mathrm{T}$, Kaukinen K, Virta LJ, et al. Refractory coeliac disease in a country with a high prevalence of clinically-diagnosed coeliac disease. Aliment Pharmacol Ther. 2014;39:418-425.
How to cite this article: Fuchs V, Kurppa K, Huhtala $\mathrm{H}$, et al. Serology-based criteria for adult coeliac disease have excellent accuracy across the range of pre-test probabilities. Aliment Pharmacol Ther. 2019;49:277-284. https://doi.org/ 10.1111/apt.15109 